\title{
Planning transport for social inclusion: An accessibility-activity participation approach
}

\author{
Jeff Allen \\ University of Toronto \\ jeff.allen@utoronto.ca \\ Steven Farber \\ University of Toronto \\ steven.farber@utoronto.ca
}

This manuscript preprint version is made available under the CC-BY-NC-ND 4.0 license:

http : //creativecommons . org/licenses/by-nc-nd/4.0/

The final published version in Transportation Research Part D: Transport and Environment can be found at https://doi.org/10.1016/j.trd.2019.102212. This paper was also presented at the 2020 Transportation Research Board (TRB) Annual Meeting.

\begin{abstract}
Social equity is increasingly becoming an important objective in transport planning and project evaluation. This paper provides a framework and an empirical investigation in the Greater Toronto and Hamilton Area (GTHA) examining the links between public transit accessibility and the risks of social exclusion, simply understood as the suppressed ability to conduct daily activities at normal levels. Specifically, we use a large-sample travel survey to present a new transport-geography concept termed participation deserts, neighbourhood-level clusters of lower than expected activity participation. We then use multivariate models to estimate where, and for whom, improvements in transit accessibility will effectively increase activity participation and reduce risks of transport-related social exclusion. Our results show that neighbourhoods with high concentrations of low-income and zero-car households located outside of major transit corridors are the most sensitive to having improvements in accessibility increase daily activity participation rates. We contend that transit investments providing better connections to these neighbourhoods would have the greatest benefit in terms of alleviating existing inequalities and reducing the risks of social exclusion. The ability for transport investments to liberate suppressed activity participation is not currently being predicted or valued in existing transport evaluation methodologies, but there is great potential in doing so in order to capture the social equity benefits associated with increasing transit accessibility.
\end{abstract}

\section{Keywords}

accessibility; activity participation; transport planning; social equity; public transit 


\section{Introduction}

A basic function of urban transportation is to enable participation in daily activities. Nevertheless, transportation planning has historically focused on increasing mobility, alleviating congestion, and reducing environmental impacts; often without consideration of whether policies directly foster widespread and equitable participation in a broad range of daily activities (Meyer \& Miller, 2001; Martens, 2016). In this paper, we argue for the importance incorporating social equity into transport planning because of the relationship between accessibility, the ease of reaching daily activity destinations, and the risks of social exclusion, which can be understood as the suppressed ability to conduct daily activities at normal levels. We base our argument on an examination of how transit accessibility is related to activity participation rates in the Greater Toronto and Hamilton Area (GTHA), and how these relationships vary by income and car ownership. Specifically, this paper consists of the following four targeted objectives.

1. Conduct exploratory spatial analysis to identify participation deserts, clusters of neighbourhoods where residents have low rates of daily activity participation, areas indicative of a risk of transportrelated social exclusion.

2. Visualize and describe the relationships between transit accessibility, socio-economic status (SES), and activity participation.

3. Further quantify the accessibility-activity participation relationship through the estimation of activitygeneration models in order to investigate the degree to which access to destinations is associated with participation in out-of-home activities. The models consider the non-linear effects of accessibility and are also stratified in order to focus specifically on the effects for low-income and zero-car households.

4. Use these models to estimate future gains in activity participation stemming from improvements in transit accessibility, and then map where gains in activity participation are most likely to occur in order to aid planning recommendations.

Our findings show that participation deserts cluster in Toronto's inner-suburbs, in particular in areas with higher concentrations of low-income and zero-car households, but without high levels of transit access. Furthermore, our regression models find a significant and positive relationship between transit accessibility and out-of-home activity participation. This relationship is strongest in low-income and zero-car households. Overall, this shows that improving transit accessibility, either through investments in public transit or intensification of land use, can increase activity participation in currently under-served and socioeconomically deprived neighbourhoods. Doing so would reduce existing inequalities in participation and contribute to improved social inclusion of the transport poor. As with many planning models used in regions around the world, these benefits are not currently being predicted or valued in the GTHA's transport evaluation methodologies, but incorporating them would work progressively towards achieving higher levels of social equity within urban environments. 


\section{Background}

\subsection{Social equity \& transport planning}

For most of the 20th century, North American transport planning was parochially focused on improving travel speeds and vehicle throughput (McNally, 2000; Meyer \& Miller, 2001). Travel demand modelling and cost-benefit analyses, the methodological paradigm for making forecasts regarding future levels of travel demand and planning new infrastructure, has predominantly focused on economic benefits (Martens, 2006). Rising concern regarding climate change and environmental degradation has led to transport research and practice incorporating environmental indicators into modelling scenarios and project evaluations. However, to date, there has been much less consideration given to social equity in transport planning, despite social outcomes being widely cited as one of the three pillars for sustainable development (along with economic growth and environmental preservation) (Feitelson, 2002; Martens, 2006; Di Ciommo \& Shiftan, 2017).

Social equity generally refers to the fairness of how the costs and benefits of a resource, such as transport, are distributed among a group of people (Pereira et al., 2017; Litman, 2019). Social equity is often framed in terms of horizontal (e.g. egalitarian) or vertical dimensions (e.g. focused on those with different levels of socio-economic status, needs, or abilities) (Litman, 2019). With regards to transport specifically, it is unreasonable to expect equal levels of opportunity or outcome across space or by population groups. The distribution of transportation networks and land-use in a region cannot be spatially uniform and will never result in equal levels of individual ability to access transport services or different types of activity destinations. As well, even if there was equal access to opportunities, travel behaviour outcomes will differ between individuals and groups due to varying preferences and lifestyles. While some levels of inequality are expected, major barriers to travel can limit people in their ability to participate in daily activities, and for some, can cause transport-related social exclusion (Lucas, 2012; Martens, 2016). Social exclusion can occur when people are obstructed from participating in activities which are important for their livelihood and well-being; and reducing risks of social exclusion is often cited as a key component for producing a fairer society (Hodgson \& Turner, 2003; Churchill \& Smyth, 2019). Ample research has shown that transport disadvantage (e.g. limited public transit service, not having regular access to a private vehicle) can compound with other types of social deprivation (e.g. low wages or unemployment, low health limiting active travel) resulting in social exclusion (Preston \& Rajé, 2007; Casas, 2007; Lucas et al., 2016). This compounding effect, often called transport poverty, can also result in positive feedback effect, worsening transport and/or social disadvantage, and therefore also perpetuate risks of social exclusion over time (Lucas, 2012).

A number of researchers have discussed how reducing the risks of social exclusion, and greater considerations of social equity more generally, should increasingly be incorporated into transport planning practice (e.g. Karner \& Niemeier, 2013; Manaugh et al., 2015). Proponents have argued for policy which reduces vulnerability to transport poverty, minimizing wide-ranging inequalities in transport accessibility, and increasing overall levels of transport accessibility of a region (e.g. Garrett \& Taylor, 1999; Martens, 2016; Pereira et al., 2017). Martens (2016), in particular, argues for more in-depth understanding the relation- 
ship between accessibility and activity participation to define sufficient levels of accessibility which limit transport-related social exclusion. However, despite this important theoretical discussion, there has been limited empirical research on how this can be implemented into existing transport planning practice.

\subsection{Accessibility \& activity participation}

Activity participation rates have been considered as a key equity variable and have been highlighted as an important outcome metric that should be analyzed during transport project evaluations (Hodgson \& Turner, 2003; Litman, 2017; Martens, 2006, 2016). While some variability in participation is inevitable, high spatial concentrations of particularly low levels of activity participation can indicate the presence of transport barriers to accessing activity destinations. Reducing barriers to activity participation is achievable through increasing accessibility (Martens, 2016), where accessibility is simply defined as how easy it is to reach activity destinations (Hansen, 1959; Geurs \& Van Wee, 2004; Páez et al., 2012). Accessibility is often measured by researchers to assess the distributional benefits and effects of urban transport systems.

Outside of the transport-equity literature, some previous empirical research has linked measures of accessibility with trip and/or activity generation rates. Results have been mixed. Some have shown that measures of accessibility are associated with increased trip-making and activity participation (Vickerman, 1974; Koenig, 1980; Thill \& Kim, 2005; Fransen et al., 2018), but other studies have also found that this association was weak or not statistically significant (Hanson \& Schwab, 1987; Ewing et al., 1996; Kitamura et al., 2001). Moreover, results vary by mode of transportation. For example, research by Cordera et al. (2017) found that greater accessibility decreases trip rates in private vehicle for journey-to-work, whereas it increases trip rates via public transit. However, much of this existing research was primarily focused on improving the overall predictive capacity of travel demand models (in which trip generation is often the first step), rather than explicitly analyzing the benefits for groups such as low-income or zero-car households who are often reliant on public transit for daily travel and have greater risks of being transport poor.

As well, the mathematical relationship between accessibility and activity participation is under-studied. However, knowing the shape of this relationship (e.g. see Figure 1) is critical for evaluating whether, where, and to what extent, accessibility improvements will have different effects towards increasing activity participation. Most previous empirical research has assumed a linear relationship between accessibility and activity participation (e.g. Cordera et al., 2017). Alternatively, theoretical work by Martens $(2006,2016)$ hypothesized that at low levels of accessibility, people struggle to reach and participate in daily activities, while at higher levels of accessibility (i.e when there are fewer travel barriers), people on average participate in more activities, but there is also greater variability, since some may choose not to participate as much, even if they are capable of doing so. Martens (2016) also argues that when sufficient levels of accessibility are achieved, there will likely be a slower increase in activity participation, as most people are able to participate in as many activities as they desire. This is visualized as the orange line in Figure 1. Expanding upon this theory, we think that there may also be a flatter relationship at the low side of the accessibility spectrum, as moving from very-low to low levels of accessibility may only have a minor effect as low levels of accessibility will still be insufficient in terms of enabling participation in many daily activ- 
ities. This is displayed in Figure 1 as a sigmoidal curve. The sigmoidal function is akin to the square root function when the steepest part of the sigmoidal curve is located where accessibility is zero. Therefore, we argue for testing different sigmoidal transformations of accessibility such as the orange and purple curves in Figure 1, alongside standard linear effects, in order to estimate where accessibility improvements will have the greatest benefit for increasing activity participation.

Figure 1: Theoretical relationships between accessibility and activity participation (linear, square root, and sigmoidal)

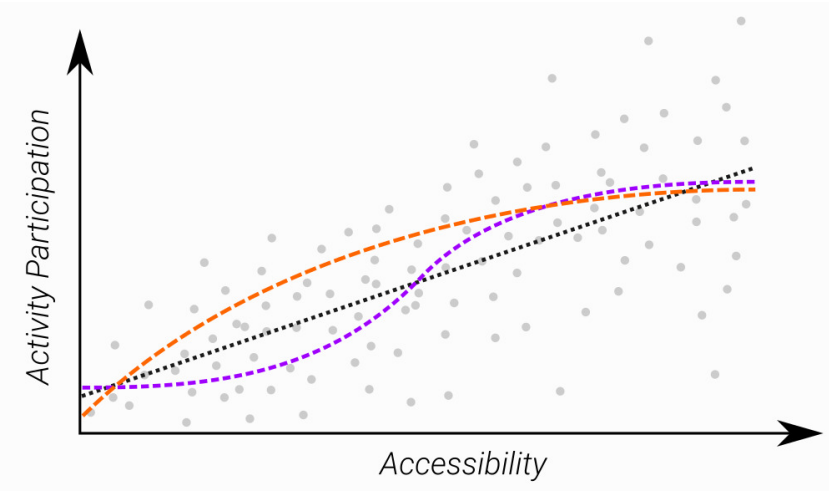

\subsection{Regional context}

Our study is situated in the Greater Toronto and Hamilton Area (GTHA), Canada's largest urban region and home to more than 7 million people. The GTHA contains six regional municipalities and thirty local municipalities. There are nine local transit agencies in region which predominantly operate surface bus and streetcar routes, and one regional transit agency, Metrolinx, which operates regional rail and bus lines. In terms of urban form, the region has been highlighted as having greater levels of density and more frequent transit service than most of it's North American counterparts. While older commercial areas and residential neighbourhoods in the GTHA are quite walkable and promote sustainable transport, they remain surrounded by swaths of post-war suburban environments in which cars are often a necessity for accessing daily activities.

Previous neighbourhood-level research linking transit accessibility and SES in the GTHA has found that, on average, neighbourhoods with greater levels of social deprivation generally have greater levels of transit accessibility than higher income neighbourhoods (e.g. El-Geneidy et al., 2016; Foth et al., 2013). This is likely driven by large counts of wealthier families who live in auto-oriented suburbs while lower-income households are more concentrated in apartment blocks along arterial roads with some existing transit service. While this neighbourhood-level analyses indicate that the region has relatively equitable transit service, recent qualitative evidence from the GTHA suggests that poor transit accessibility is responsible for many to have reduced satisfaction and participation in essential daily activities such as employment, medical appointments, and leisure (Sengupta et al., 2013; Hertel et al., 2015). Quantitative research on travel behaviour in the GTHA as well as other Canadian cities have found that individuals with greater 
barriers to travel have significantly lower levels of activity participation. For example, previous research has highlighted travel barriers for low-income women (McCray \& Brais, 2007), single parents (Páez et al., 2013), post-secondary students (Allen \& Farber, 2018), the elderly (Roorda et al., 2010), and refugees (Farber et al., 2018). In terms of scale, Litman (2003) estimated that one in three Canadian households have at least one member who regularly has barriers to daily travel, and Allen and Farber (2019b) estimated that 500,000 individuals living below the poverty line in the GTHA also live in neighbourhoods with poor transit accessibility. This research is especially concerning given that income distributions are increasingly polarized, and many socioeconomically deprived neighbourhoods are now within suburban environments with relatively lower levels of transit provision (Ades et al., 2012; Hulchanski, 2010; Walks, 2013). Figure 2 shows that low-income neighbourhoods tend to be clustered within certain middle-ring suburbs in Toronto, as well as in central parts of Hamilton and Oshawa.

Figure 2: Map of major transit lines and low-income households in the GTHA

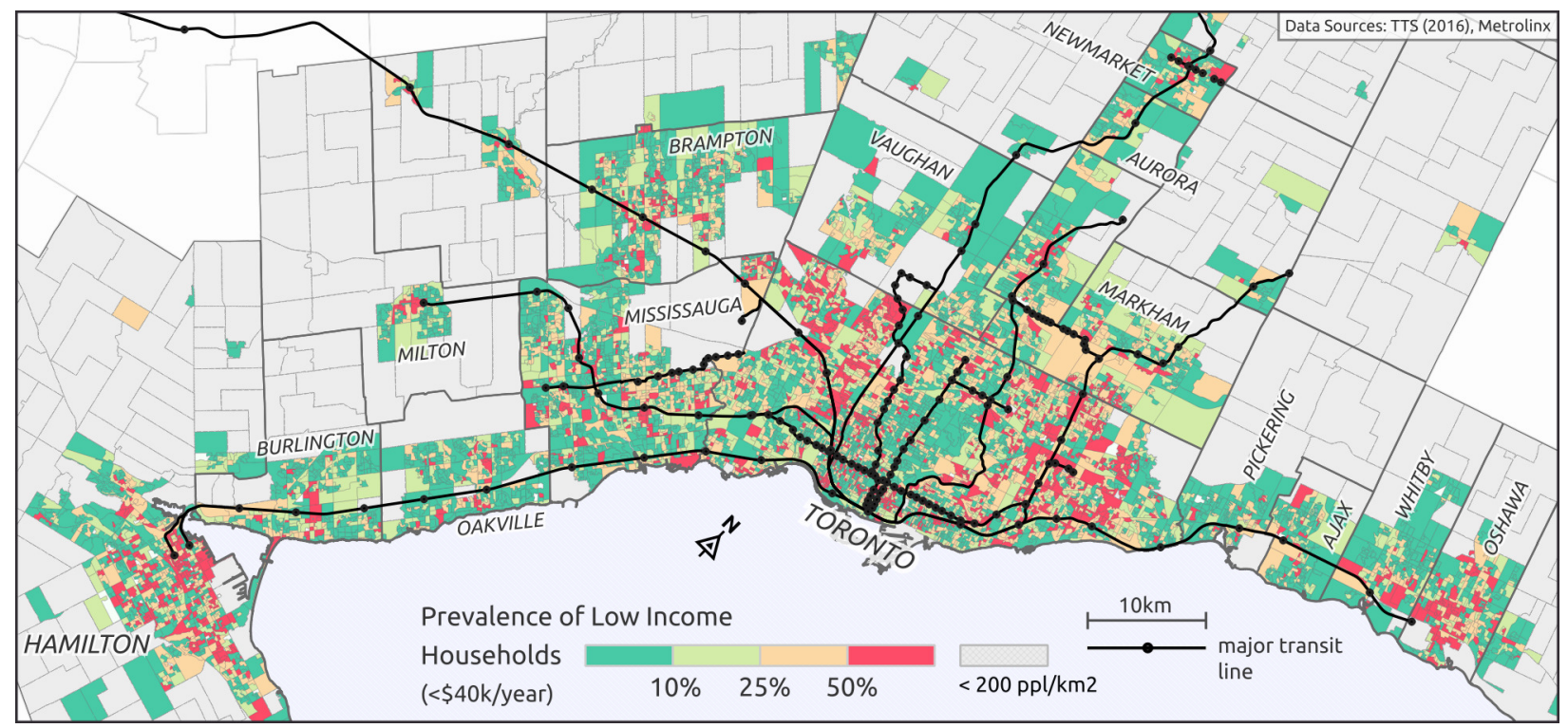

\section{Data sources}

Primary data for this project is from the 2016 Transportation Tomorrow Survey (TTS), a large sample household travel survey primarily designed to develop estimates of travel demand into long-range planning models in the GTHA. Overall, the TTS aims to collect a 5\% sample of households in the region, although sampling rates vary geographically, with Hamilton only consisting of a 3\% sample, on the low end. We use the travel diary portion of the TTS to count the number of daily activities per person, which is the sum of out-of-home destinations, without double-counting activities of the same purpose which occur at the same location. Figure 3 graphically exemplifies how daily activity participation rates were derived from the travel survey for different individuals. 
Figure 3: Examples of how activity participation is quantified from the travel diary

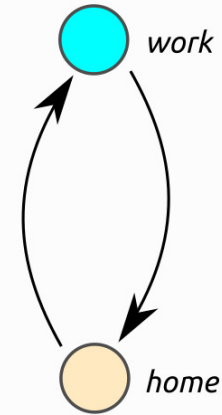

2 trips

1 activity

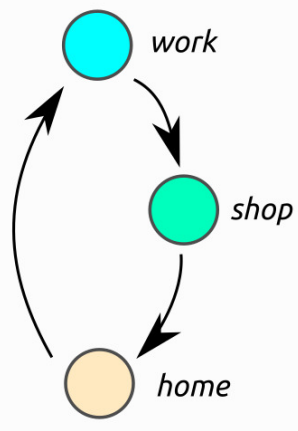

3 trips

2 activities

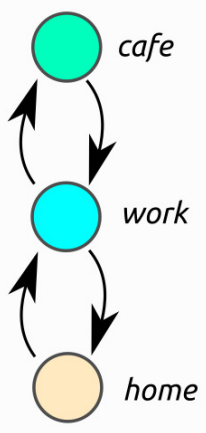

4 trips

2 activities

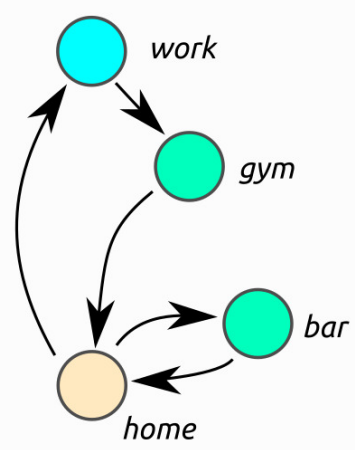

5 trips

3 activities

Importantly, the TTS also includes a set of expansion factors to produce population level estimates. The weighting method takes into account dwelling type, household size, and the distribution of the population by age and gender matching the distributions with the 2016 Canadian census of population. We subset our sample to individuals who are 18 years and older. This results in a sample size of $n=247,453$ individuals pertaining to a population of $N=5,345,419$. Table 1 describes the TTS data used in this study.

To augment the TTS, we compute transit accessibility measures at the Dissemination Area (DA) zonal level, the smallest geography which can be linked to households in the TTS. DAs are designed to a have a population of 400-700 people and typically consist of a few city blocks. We compute commonly used place-based measures of access to employment, that count the number of jobs that are reachable from each DA in the region, using a gravity model to weight nearby jobs greater than those which are further away (Hansen, 1959; Geurs \& Van Wee, 2004). The distributions of employment are theorized to be a proxy for many other potential destination types (e.g. services, shopping, etc.). Accessibility is computed as follows:

$$
A_{i}=\sum_{j=1}^{J} O_{j} f\left(t_{i, j}\right)
$$

Where $A_{i}$ is the accessibility measure for zone $i, O_{j}$ is the employment count in census tract $j$ from the 2016 Canadian census, and $t_{i, j}$ is the travel time from $i$ to $j . f\left(t_{i, j}\right)$ is a decreasing function which weights nearby job opportunities greater than those further away. For this analysis, we use an inverse-power function as it showed a greater correlation with transit mode share than other functional forms.

$$
f\left(t_{i, j}\right)=180\left(90+t_{i, j}\right)^{-1}-1
$$

This function returns a weight of 0.5 for a 30 minute trip, ranging from a weight of 1 at $t_{i, j}=0$ and a weight of 0 at $t_{i, j} \geq 90$. 30 minutes is approximately the median commute time in the GTHA, across all travel modes. This basis of returning a value of 0.5 for the median commute time has been used previously 
in the literature for its close approximation to fitted gravity curves as well as for its ease of interpretation (Östh et al., 2016; Allen \& Farber, 2019a).

Transit travel times, $t_{i, j}$, were computed using OpenTripPlanner, populated with OpenStreetMap pedestrian networks and GTFS packages circa May 2016, to align with the 2016 census and TTS collection periods. Computed travel times include the time walking to and from stops, waiting for a transit vehicle, time spent travelling in a transit vehicle, and any time spent transferring. In order to account for time-varying transit schedules, we follow precedent in the literature (e.g. Owen \& Levinson, 2015; Farber \& Fu, 2017) to compute $A_{i}$ for every minute from $7 \mathrm{am}$ to $9 \mathrm{am}$, and then calculate an average level of accessibility over this period. Measures of $A_{i}$ are then linked to the household locations of each respondent in the TTS to allow for individual and neighbourhood level analyses.

Table 1: Summary statistics of adults in the GTHA from the 2016 Transportation Tomorrow Survey $(n=$ $247,453, N=5,345,419)$

\begin{tabular}{|c|c|c|c|}
\hline Variable & Amount & Variable & Amount \\
\hline Household income per year & & Activities per day & \\
\hline$\$ 0$ to $\$ 14,999$ & $3.5 \%$ & 0 activities & $24.1 \%$ \\
\hline$\$ 15,000$ to $\$ 39,999$ & $12.1 \%$ & 1 activity & $48.1 \%$ \\
\hline$\$ 40,000$ to $\$ 59,999$ & $13.3 \%$ & 2 activities & $17.4 \%$ \\
\hline$\$ 60,000$ to $\$ 99,999$ & $21.3 \%$ & 3 or more activities & $10.4 \%$ \\
\hline$\$ 100,000$ to $\$ 124,999$ & $11.1 \%$ & Mean activities per day & 1.21 \\
\hline$\$ 125,000$ and above & $20.2 \%$ & Sex & \\
\hline Decline / don’t know & $18.4 \%$ & Female & $52.1 \%$ \\
\hline Vehicles per adult $(V A)^{*}$ & & Male & $47.9 \%$ \\
\hline $\mathrm{VA}=0$ & $11.1 \%$ & Age & \\
\hline $0<\mathrm{VA}<0.5$ & $11.4 \%$ & $18-30$ & $21.9 \%$ \\
\hline $\mathrm{VA}=0.5$ & $23.2 \%$ & $31-65$ & $62.3 \%$ \\
\hline $0.5<\mathrm{VA}<1$ & $15.6 \%$ & $66-75$ & $9.8 \%$ \\
\hline $\mathrm{VA} \geq 1$ & $38.7 \%$ & $76+$ & $6.1 \%$ \\
\hline Mean household size & 3.24 & Has transit pass ${ }^{\dagger}$ & $23.5 \%$ \\
\hline Household type $e^{\S}$ & & Has driver's license & $82.1 \%$ \\
\hline Single person & $11.5 \%$ & Employment status & \\
\hline One-generation & $23.1 \%$ & Full time & $50.1 \%$ \\
\hline Two-generation & $52.7 \%$ & Part time & $10.1 \%$ \\
\hline Multi-generation & $8.3 \%$ & Works from home & $4.7 \%$ \\
\hline Other & $4.4 \%$ & Not employed & $35.0 \%$ \\
\hline Dwelling type & & Student status & \\
\hline Detached house & $58.3 \%$ & Not a student & $90.0 \%$ \\
\hline Townhouse & $31.5 \%$ & Full time student & $7.4 \%$ \\
\hline Apartment & $10.2 \%$ & Part time student & $2.6 \%$ \\
\hline \multicolumn{4}{|c|}{ * Classified as such to account for different levels of auto-deficits (e.g. Blumenberg, Brown, \& Schouten, 2018) } \\
\hline $\begin{array}{l}\S \text { This variable is derived based on the } \\
\text { members, after all household members a }\end{array}$ & $\begin{array}{l}\text { es in each house } \\
\text { ranked in order }\end{array}$ & $\begin{array}{l}\text { Id, where a "generation" is when the } \\
\text { ording to age. }\end{array}$ & is at least an 18 year gap between two \\
\hline
\end{tabular}




\section{Mapping activity participation deserts}

We begin our analysis by identifying participation deserts, clusters of neighbourhoods where residents have lower than average rates of daily activity participation. For this analysis, we first map the mean level of activity participation at a DA level in the region (see the top of Figure 4). Secondly, we use an exploratory spatial analysis technique to detect clusters (i.e. hotspots) of high and low levels of participation in the region. Specifically, we compute the local Getis-Ord statistic, $G_{i}^{*}$, (Getis \& Ord, 1992) for the average number of trips per person in each Dissemination Area, $i$, in the region. $G_{i}^{*}$ can be interpreted as the percentage of the total sum of participation in the region that is found in the surrounding neighbourhoods of $i$. This is computed as follows:

$$
G_{i}^{*}=\frac{\sum_{j} w_{i, j} x_{j}}{\sum_{j} x_{j}}
$$

Where $x$ is the mean activity participation rate in a DA and $W_{i, j}=\left\{w_{i, j}\right\}$ is a row-normalized Queen connectivity matrix. We can test whether the observed $G_{i}^{*}$ values are significantly different to those we would expect to see under an assumption of a spatially random distribution of daily activity participation rates. $G_{i}^{*}$ and associated $p$-values were computed using pysal (Rey \& Anselin, 2007). Important to note is that this type of calculation assumes that the value in each DA is for the population, not a sample estimate, so this map should only be considered as exploratory given the uncertainty that comes with sampling over space.

The bottom half of Figure 4 shows clusters of high and low activity participation. This shows that areas of low activity participation tend to cluster in less-central parts of the region. Through visual inspection, these areas tend to be post-war, auto-oriented suburban environments, but less concentrated in newer (i.e. 21st century) suburbs. Visually comparing with Figure 2, these clusters of low activity participation also appear to align with areas with higher proportions of low income households. The locations of participation deserts therefore follow directly from the theoretical framework on transport-related social exclusion, that low-incomes and low-levels of transit access, result in inaccessibility and barriers to participation in daily activities. 
Figure 4: Activity participation deserts in the GTHA

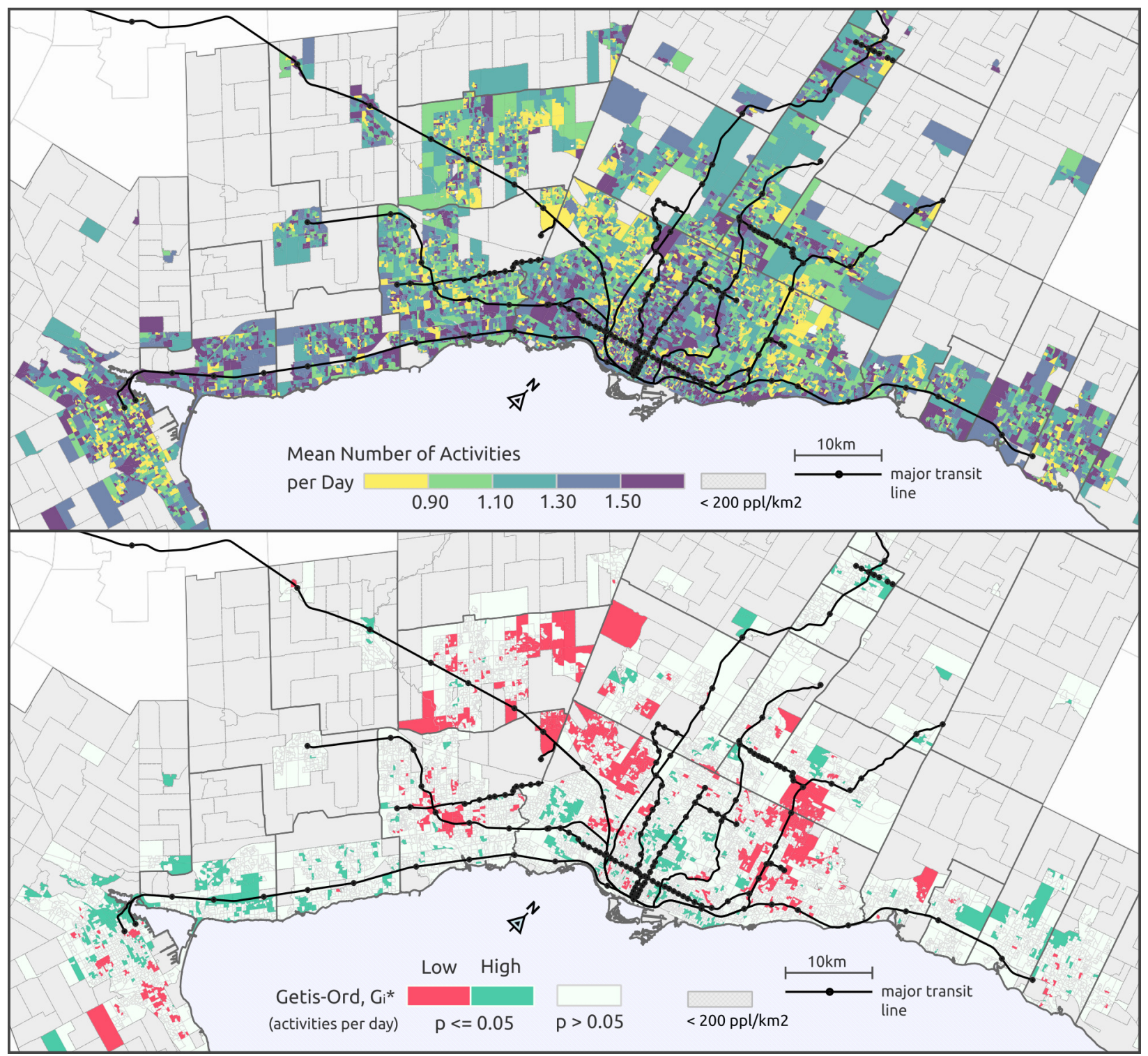

\section{Plotting relationships between accessibility, income, \& activity par- ticipation}

Figure 5 (left) displays the relationship between transit accessibility and household income. Similar to previous research (e.g. Foth et al., 2013; El-Geneidy et al., 2016), we find that overall, low income households are located in areas of better transit accessibility than higher income households. This is an indication that lower-income households try to locate in neighbourhoods with good transit access, likely partly due to limited car ownership. As well, many of the densest apartment neighbourhoods that attract lower-income 
households tend to be located centrally or on major arterials with high levels of transit service compared to the locations of less-affordable single-detached homes. Additionally, this indicates preference among higher income families for suburban, automobile dependent locales. However, for households without cars, we see an opposite trend (red points), that low-income households without cars are likely to be in relatively worse areas of transit access than higher-income households without cars. This suggests that higher income households are more likely to buy or lease a car when residing in areas of lower transit access to overcome this lack of alternative mobility options; while lower-income households are often not able to afford to do so. It also shows that wealthier households who choose not to own a vehicle, are able overcome this mobility barrier by paying to live in high accessibility neighbourhoods.

Figure 5 (right) shows the average rate of activities per day for individuals in each income group. Clearly, people in higher income brackets participate in more daily activities, on average. This is likely due to the costs of travel, higher income residents being more likely to be employed (employed people take more trips), as well as the costs of participating in certain activities (e.g. shopping, recreation). These costs likely deter participation for those in lower income households. We also see that the gap in participation rates between zero-car and other respondents is largest in the two lowest income categories. This is suggestive that wealthier households are more able to overcome the mobility-barrier of not owning a car, compared to poorer households.

Figure 5: Left: Mean and median level of transit accessibility for different household income categories. Right: Mean rate of activities per day for different household income categories.

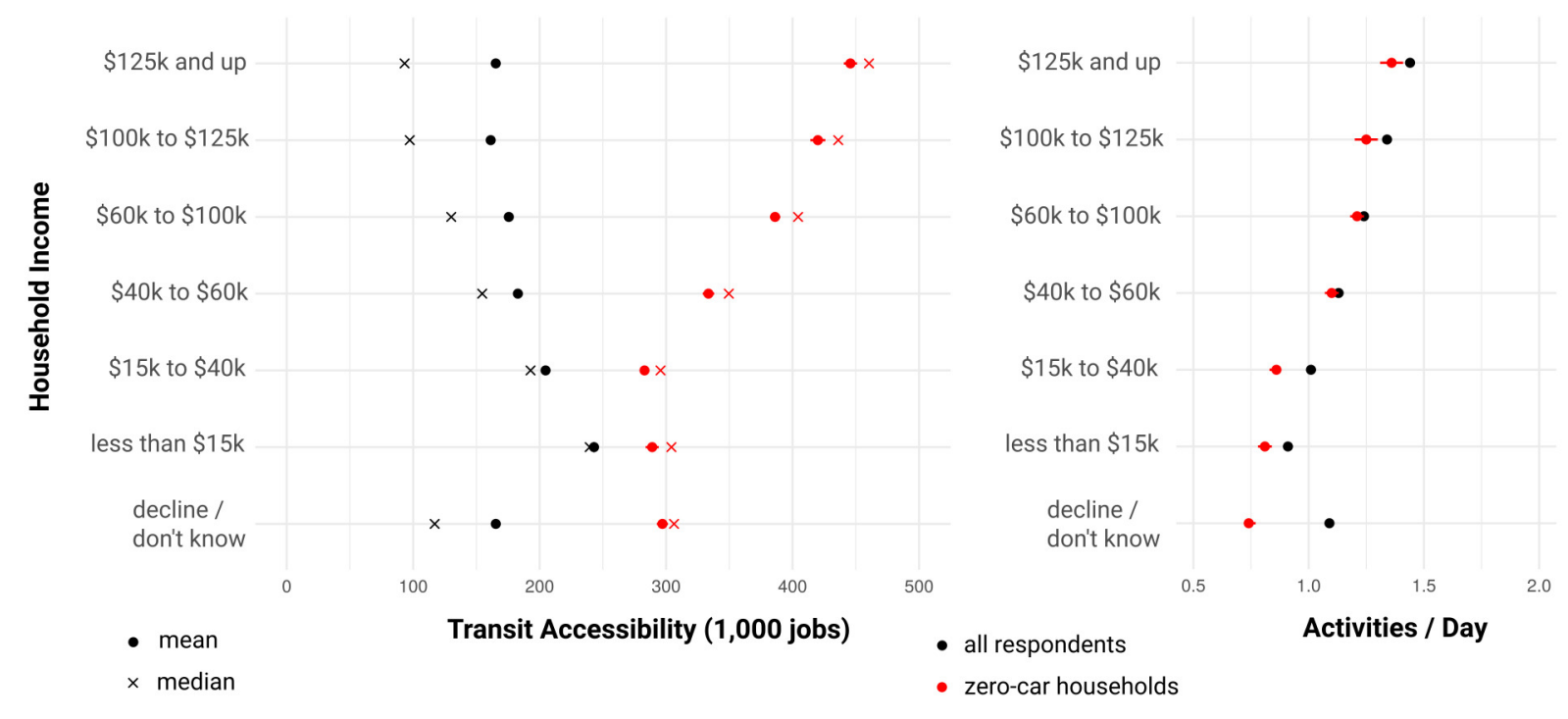

In Figure 6, we visualize the relationship between transit accessibility and activity participation. This is plotted for the overall population, as well as subset for low-income and zero-car households. This shows that when averaged across the entire population, activity participation does not seem to be very closely related with transit accessibility. In fact, it appears that many individuals with high levels of activity par- 
ticipation tend to live in low-access parts of the city, presumably achieving these high rates through automobile use. Even among low-income households, accessibility and activity participation are not closely related. $66 \%$ of trips by individuals in low-income households are made by car. For zero-car households, there is a positive relationship between transit accessibility and activity participation. The trend among zero-car households extends to those that are specifically low-income. At the highest levels of accessibility, activity participation among zero-car, low-income, and all households equalizes. High levels of transit accessibility therefore diminishes the participation-disadvantage of being low-income and/or not owning a vehicle.

Figure 6: Relationships between transit accessibility and activity participation.

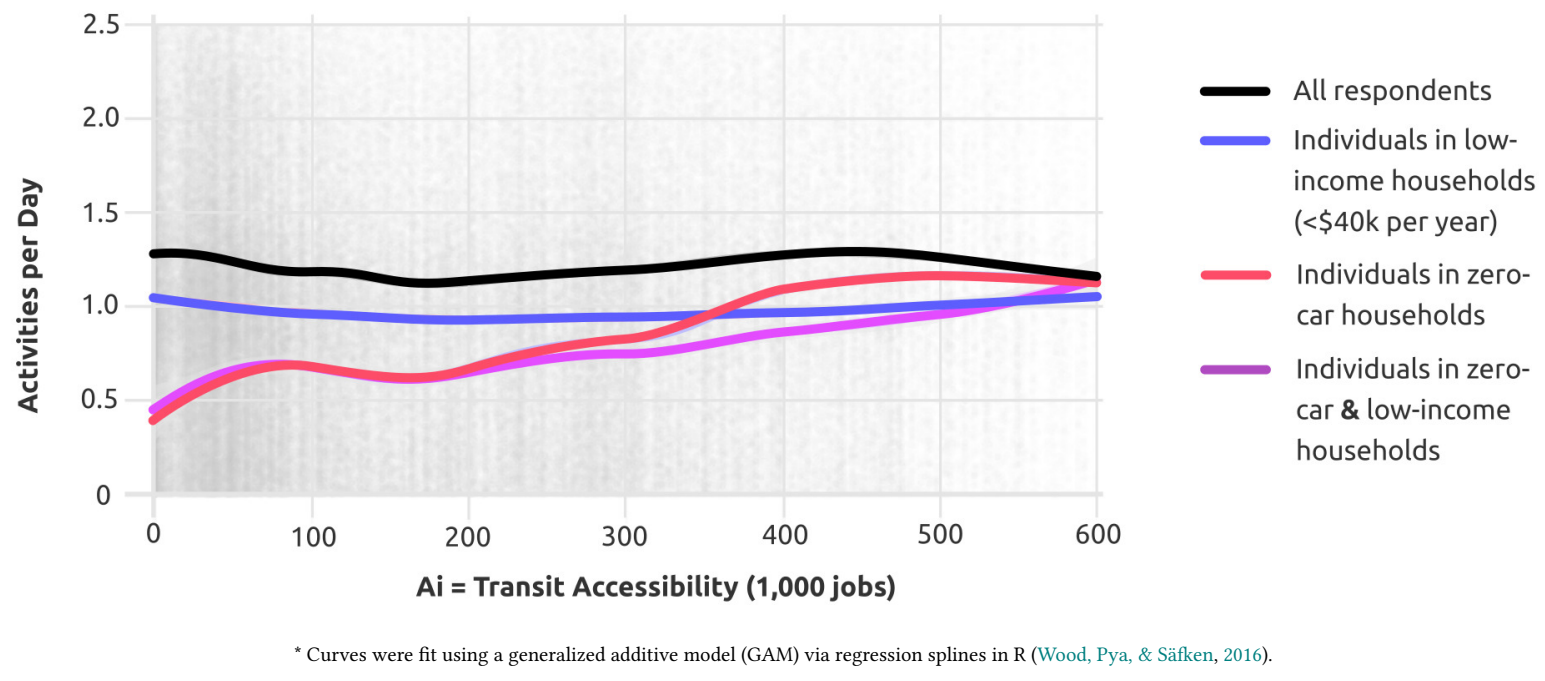

\section{Activity participation models}

We now quantify the accessibility-participation relationship through the estimation of activity-generation models. These models estimate the marginal effect of transit accessibility on the number of daily outof-home activities, both for the overall population as well as dis-aggregated by income and levels of carownership, while also controlling for other factors that affect participation such as age, household structure, and employment status.

\subsection{Model definitions}

The dependent variables are count data and are modelled best using negative binomial regression due to over-dispersion. Zero-inflated models were deemed unnecessary due to lack of abundance of zero-values in the data. The models are estimated via maximum likelihood estimation using the glm. nb function from the MASS package in R (see Venables et al. (2002) for more detail about this type of model and its estimation in R). Goodness of fit was assessed with the Akaike Information Criterion (AIC) and the $\rho$ parameter (Ben- 
Akiva \& Lerman, 1985). The same goodness of fit statistics have been used in other studies in the GTHA examining trip generation and activity participation rates (Roorda et al., 2010; Allen \& Farber, 2018). Model residuals were also tested for spatial autocorrelation, but they were found to be quite low (Moran's I $<$ 0.03), so spatial models were not deemed necessary.

In negative binomial regression, each independent variable is associated with a single regression coefficient, implying that impacts of accessibility on activity generation are homogeneous for all levels of accessibility. This is unlikely to be true in reality, as similarly sized gains in accessibility will have different effects on activity generation for those with very low levels of access, medium levels of access, or high levels of access (Martens, 2006, 2016). Given our theoretical basis (Figure 1), as well as our descriptive results (Figure 6), we test standard linear effects of accessibility, second to fifth order polynomial transformations, as well as various sigmoidal transformations. The latter assume that effects are largest in the middle of the accessibility distribution, but are relatively flat in the upper and lower tails. Assuming the following generalized form of a negative binomial activity generation model:

$$
\ln (y)=\alpha+f(A)+\beta X+\epsilon
$$

The linear effect of accessibility is simply $f(A)=\beta_{A} A$, polynomial is $f(A)=\sum_{k \in K} \beta_{A, k} A^{k}$, and a sigmoidal transformation based on the logistic function is calculated as

$$
f(A)=\beta_{A} \frac{1}{1+e^{\left(-k\left(A-A_{m}\right)\right)}}
$$

where $\beta_{A}$ can be interpreted as the height of the sigmoidal curve, $k$ is the steepness of the curve, and $A_{m}$ is the value at the curve's midpoint (i.e. the value of $A$ where the slope is at its maximum). However, we do not know, a priori, where the various inflections in the curve may occur, so we adopt a modelling strategy that tests various sigmoidal transformations of accessibility that enter into our activity generation models. A brute-force parameter sweep is used to cycle through values of $A_{m}$ and $k$, allowing $\beta_{A}$ to be estimated by maximum likelihood, returning the model where $\rho$ is maximized.

\subsection{Model results}

Model results for the linear and best-fitting sigmoidal accessibility transformation are displayed in Table 2. In general, the sigmoidal model obtains a slightly higher level of fit, with only minor differences in coefficients for non-accessibility variables. We do not present polynomial transformations since the results were very similar. Estimated model parameters, $\beta$, as well as incident rate ratios (IRR) are displayed in Table 2. The IRR for an independent variable is computed as $\operatorname{IRR}=e^{\beta}$. It can be interpreted as the multiplicative increase or decrease in the daily activity participation rate caused by a 1 unit increase for numerical variables or by changing groups for categorical variables. For example, someone who is a full-time student is expected to have an activity participation rate 1.27 times greater than a non-student, holding all other 
variables constant. A model estimate greater than 0 and an IRR greater than 1 indicate that the variable has a positive effect on activity participation.

Table 2: Activity participation global model results $(\mathrm{n}=247,453)$

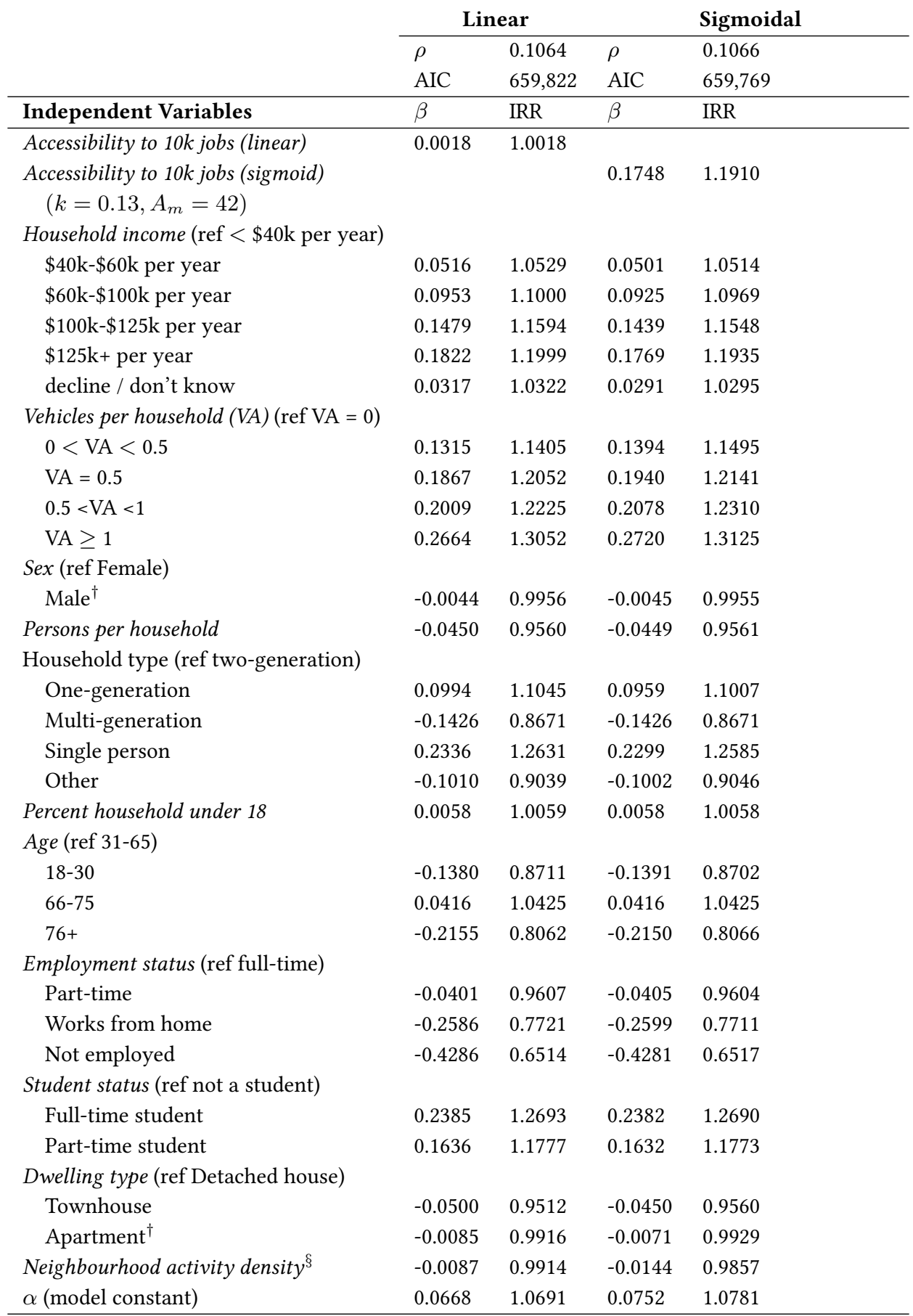

$\dagger$ All variables were significant at the 0.001 level except for those indicated with a $\dagger$, which were not significant at the 0.1 level

$\S$ Local built environment control derived as the weighted sum of standardized values of population density, business density, and employment density in each Dissemination Area. Similar localized density measures have been used in previous studies to examine their relationship with travel behaviour (Cervero \& Kockelman, 1997), and specifically on trip and activity generation (Zhang et al., 2019). 
The global models show that transit accessibility has a small but significant effect on activity participation. The small effect sizes of accessibility are expected since participation rates are usually low (e.g. on average 1 to 2 activities per day) and many activities are obligatory and will be un-related to transit accessibility improvements. But importantly, the models indicate that overall, improvements in transit accessibility are associated with people participating in a greater number of daily activities. Looking at the model with the sigmoidal transformation, we see that the effect of accessibility on participation is strongest at $A=420,000$ jobs, which maps to neighbourhoods outside of the city centre, but located along rapid transit corridors.

Income and car ownership are also shown to be positively associated with activity participation. Compared to the reference income category $(<\$ 40 \mathrm{k}$ per year), moving up each income level approximately corresponds to 5 percent increases in participation rates. At the highest bracket ( $\$ 125 \mathrm{k}+$ per year), people participate in 1.19 times as many daily activities as the lowest income bracket, all else being equal. The effects of car ownership are somewhat stronger, where moving from no cars to less than 1 cars per 2 adults is associated with a $14 \%$ increase in participation, while moving to a car-abundant household with one or more cars per adult, is associated with a $30 \%$ increase in participation rates, all else equal. In general, the model results corroborate both existing theory on transport poverty (e.g. Lucas, 2012) as well as the descriptive findings in the previous section of this paper.

\subsection{Stratified models}

To further understand the effects of transit accessibility for those groups who are more vulnerable to transport poverty, we stratify the models by income and car-ownership. This results in 30 separate models (six income groups by five groups of car-ownership) from which we examine the magnitude and statistical significance of the accessibility coefficients to understand how they vary by group. Each model includes all independent variables displayed in Table 2. The shape and significance of the effects of accessibility for each sub-model is displayed in Figure 7 (detailed model summaries of each stratified model, including goodness-of-fit, are included in the Appendix). We only present results for the sigmoidal models, as they were found to be a better fit than the linear models in all cases.

Figure 7 shows that for zero-car households, transit accessibly has a significant and positive effect on activity participation rates, for all but one income bracket. However, there are substantially more lower-income households without cars than there are zero-car households in the middle- or higher-income brackets. We also find that low-income households with at least 0.5 cars per adult do not see a significant effect of accessibility on activity participation. These results correspond with the bi-variate results found in Section 5. Interesting as well is that some higher income groups and households with cars are also more likely to experience gains in activity participation if they live in accessible areas. This could be because living in more active urban environments encourages more out-of-home activities, which wealthier households are more able to afford to participate in, regardless of travel-related barriers. 
Figure 7: Shape and significance of the fitted sigmoidal transformations of accessibility, $f(A)$, predicting activity participation for each sub-model

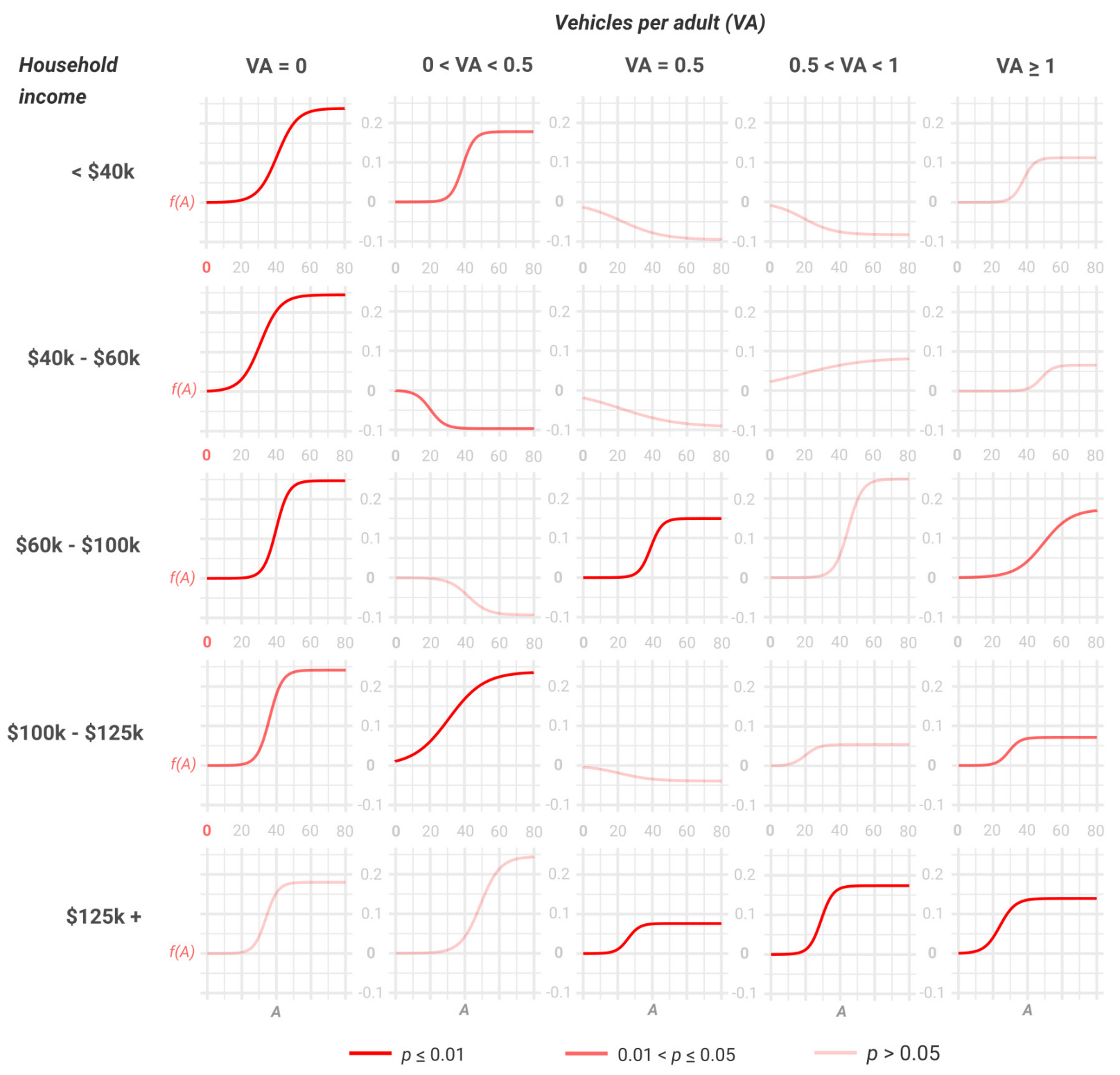

\section{Exploring effect sizes: estimating activity gains from improvements in accessibility}

We use the coefficients from the stratified models to estimate how individuals living in different types of households are likely to respond to transit accessibility improvements, conditional on their household 
income, automobile ownership, and current levels of transit accessibility. We aggregate these estimated activity generations by SES group as well as by neighbourhood to explore where, and for whom, changes in transit accessibility are likely to result in the highest levels of activity gains.

Specifically, for each observation in our sample, $i$, we can use the stratified model pertaining to their class of income and car-ownership to estimate their current $\hat{y}_{c, i}$ and projected $\hat{y}_{p, i}$ levels of activity participation given their current and projected levels of accessibility, respectfully. The predicted change in activity participation due to a change in accessibility is calculated simply as $\Delta \hat{y}_{i}=\hat{y}_{p, i}-\hat{y}_{c, i}$.

We compute $\Delta \hat{y}_{i}$ for each individual in our sample for five different levels of change in accessibility: a $10 \%$ increase, a $25 \%$ increase, and absolute increases of 50,000 jobs, 100,000 job, and 200,000 jobs. The sizes of these accessibility increases are informed by previous work that investigated a number of GTHA rapid transit expansions (Farber \& Grandez, 2017). The smaller gains in accessibility (10\% or 50k jobs) are roughly the gains that would be achieved via moderate improvements in existing transit service (e.g. adding dedicated bus lanes or more frequent service), while the larger scenarios could be achieved from investments in higher-order transit infrastructure (e.g. well-connected rapid transit running on separated grades).

\subsection{Activity gains by household income and auto-ownership}

First, we aggregate estimated potential accessibility gains by household income and car-ownership levels (Table 3). The cells on the right indicate the number of new activities gained for each scenario for each mutually exclusive subset of household income and car-ownership. The rows with 0s are for sub-models with insignificant accessibility coefficients (i.e. where $p>0.05$ ). The table shows that zero-car households in particular are likely to achieve substantial gains in activity participation if given improvements in transit accessibility.

Table 3: Estimated gains in activity participation per day for different accessibility improvement scenarios

\begin{tabular}{|c|c|c|c|c|c|c|c|c|}
\hline \multirow{2}{*}{$\begin{array}{l}\text { Household } \\
\text { income }\end{array}$} & \multirow{2}{*}{$\begin{array}{l}\text { Vehicles per } \\
\text { adult (VA) }\end{array}$} & \multirow[b]{2}{*}{$\mathbf{N}$} & \multirow{2}{*}{$\begin{array}{l}\text { Total daily } \\
\text { activities }\end{array}$} & \multicolumn{5}{|c|}{ Increase in activities for increases in $A_{i}$} \\
\hline & & & & $10 \%$ & $25 \%$ & $50 \mathrm{k}$ & 100k & $200 \mathrm{k}$ \\
\hline$<\$ 40 \mathrm{k}$ & $\mathrm{VA}=0$ & 264,475 & 217,867 & 3,900 & 9,200 & 5,400 & 11,200 & 22,100 \\
\hline$<\$ 40 \mathrm{k}$ & $0<\mathrm{VA}<0.5$ & 109,122 & 92,225 & 800 & 2,300 & 1,300 & 3,300 & 7,700 \\
\hline$<\$ 40 \mathrm{k}$ & $\mathrm{VA}=0.5$ & 217,567 & 216,610 & 0 & 0 & 0 & 0 & 0 \\
\hline$<\$ 40 \mathrm{k}$ & $0.5<\mathrm{VA}<1$ & 52,502 & 47,554 & 0 & 0 & 0 & 0 & 0 \\
\hline$<\$ 40 \mathrm{k}$ & $\mathrm{VA}>=1$ & 189,582 & 240,964 & 0 & 0 & 0 & 0 & 0 \\
\hline$\$ 40 \mathrm{k}-\$ 60 \mathrm{k}$ & $\mathrm{VA}=0$ & 85,983 & 94,397 & 1,500 & 3,200 & 2,300 & 4,200 & 6,800 \\
\hline$\$ 60 \mathrm{k}-\$ 100 \mathrm{k}$ & $\mathrm{VA}=0$ & 92,831 & 112,578 & 2,900 & 6,000 & 3,800 & 6,800 & 10,500 \\
\hline$\$ 100 \mathrm{k}-\$ 125 \mathrm{k}$ & $\mathrm{VA}=0$ & 27,407 & 34,533 & 600 & 1,200 & 800 & 1,400 & 1,900 \\
\hline$\$ 125 k+$ & $\mathrm{VA}=0$ & 27,034 & 37,000 & 0 & 0 & 0 & 0 & 0 \\
\hline Decline & $\mathrm{VA}=0$ & 97,645 & 70,984 & 500 & 900 & 800 & 1,400 & 2,400 \\
\hline All others & All others & $4,181,271$ & $5,295,963$ & 12,700 & 30,700 & 26,700 & 60,100 & 161,200 \\
\hline Overall popula & & $5,345,419$ & $6,460,674$ & 23,000 & 53,500 & 41,100 & 88,400 & 212,700 \\
\hline
\end{tabular}


We next examine how the total gain in activity participation is distributed between groups (see Table 4). We see that those in low-income and zero-car households make up less than $5 \%$ of the overall population, and currently only $3.37 \%$ of the current activity participation in the region, but would constitute from $10 \%$ to $17 \%$ of the total gain in new activity participation, depending on the scenario. This shows that investments specifically aimed at serving low-income and zero-car households can expect to see the largest gains in induced activity participation. Whereas a relatively lower share of gains will be achieved in more affluent neighbourhoods, especially for those with cars.

Table 4: Distribution of gains in activity participation by SES groups

\begin{tabular}{|c|c|c|c|c|c|c|c|c|}
\hline \multirow{2}{*}{$\begin{array}{l}\text { Household } \\
\text { income }\end{array}$} & \multirow{2}{*}{$\begin{array}{l}\text { Vehicles per } \\
\text { adult (VA) }\end{array}$} & \multirow[b]{2}{*}{$\mathbf{N}$} & \multirow{2}{*}{$\begin{array}{l}\text { Total daily } \\
\text { activities }\end{array}$} & \multicolumn{5}{|c|}{ Increase in activities for increases in $A_{i}$} \\
\hline & & & & $10 \%$ & $25 \%$ & $50 \mathrm{k}$ & 100k & $200 k$ \\
\hline$<\$ 40 \mathrm{k}$ & $\mathrm{VA}=0$ & $4.95 \%$ & $3.37 \%$ & $17 \%$ & $17 \%$ & $13 \%$ & $13 \%$ & $10 \%$ \\
\hline$<\$ 40 \mathrm{k}$ & $0<\mathrm{VA}<0.5$ & $2.04 \%$ & $1.43 \%$ & $4 \%$ & $4 \%$ & $3 \%$ & $4 \%$ & $4 \%$ \\
\hline$<\$ 40 \mathrm{k}$ & $\mathrm{VA}=0.5$ & $4.07 \%$ & $3.35 \%$ & $0 \%$ & $0 \%$ & $0 \%$ & $0 \%$ & $0 \%$ \\
\hline$<\$ 40 \mathrm{k}$ & $0.5<\mathrm{VA}<1$ & $0.98 \%$ & $0.74 \%$ & $0 \%$ & $0 \%$ & $0 \%$ & $0 \%$ & $0 \%$ \\
\hline$<\$ 40 \mathrm{k}$ & $\mathrm{VA}>=1$ & $3.55 \%$ & $3.73 \%$ & $0 \%$ & $0 \%$ & $0 \%$ & $0 \%$ & $0 \%$ \\
\hline$\$ 40 \mathrm{k}-\$ 60 \mathrm{k}$ & $\mathrm{VA}=0$ & $1.61 \%$ & $1.46 \%$ & $7 \%$ & $6 \%$ & $6 \%$ & $5 \%$ & $3 \%$ \\
\hline$\$ 60 \mathrm{k}-\$ 100 \mathrm{k}$ & $\mathrm{VA}=0$ & $1.74 \%$ & $1.74 \%$ & $13 \%$ & $11 \%$ & $9 \%$ & $8 \%$ & $5 \%$ \\
\hline$\$ 100 \mathrm{k}-\$ 125 \mathrm{k}$ & $\mathrm{VA}=0$ & $0.51 \%$ & $0.53 \%$ & $3 \%$ & $2 \%$ & $2 \%$ & $2 \%$ & $1 \%$ \\
\hline$\$ 125 k+$ & $\mathrm{VA}=0$ & $0.51 \%$ & $0.57 \%$ & $0 \%$ & $0 \%$ & $0 \%$ & $0 \%$ & $0 \%$ \\
\hline Decline & $\mathrm{VA}=0$ & $1.83 \%$ & $1.10 \%$ & $2 \%$ & $2 \%$ & $2 \%$ & $2 \%$ & $1 \%$ \\
\hline All others & All others & $78.22 \%$ & $81.97 \%$ & $55 \%$ & $57 \%$ & $65 \%$ & $68 \%$ & $76 \%$ \\
\hline Total & & $100.00 \%$ & $100.00 \%$ & $100 \%$ & $100 \%$ & $100 \%$ & $100 \%$ & $100 \%$ \\
\hline
\end{tabular}

\subsection{Activity gains by neighbourhood}

Next, we aggregate estimated gains in activity participation by neighbourhood. This allows us to highlight where improvements in accessibility will have the greatest benefit in terms of increasing activity participation rates.

Figure 8 (top) displays the estimated gain in activity participation in each DA from a hypothetical increase of $100 \mathrm{k}$ jobs accessibility. The darker the blue on the map, the greater the gains in activity participation. This pattern is largely governed by three factors pertaining to each neighbourhood: the number of lowincome households, the number of zero-car households, and the baseline levels of accessibility in the DA. The latter is a result of the sigmoidal shape of the access-participation relationship, which predicts that the biggest effect of accessibility will occur in areas with already moderate levels of access. We see that accessibility increases activity rates most in central parts of the region, and especially in low-income areas not directly served by rapid transit. Conversely, there are many light-blue areas in the GTHA's outer suburbs. These are places where accessibility currently is low, and so an increase in access moves neighbourhoods along the flatter part of the sigmoidal curve. These are also places with relatively high levels of automobile ownership, leading to an insensitivity to transit improvements, from the perspective of net change in overall activity generations. 
Figure 8: Top: Density in activity generation resulting from an improvement in accessibility of 100k jobs. Bottom: Ditto, but only showing neighbourhoods with low levels of activity participation (mean individual activity participation $<1$ per day)

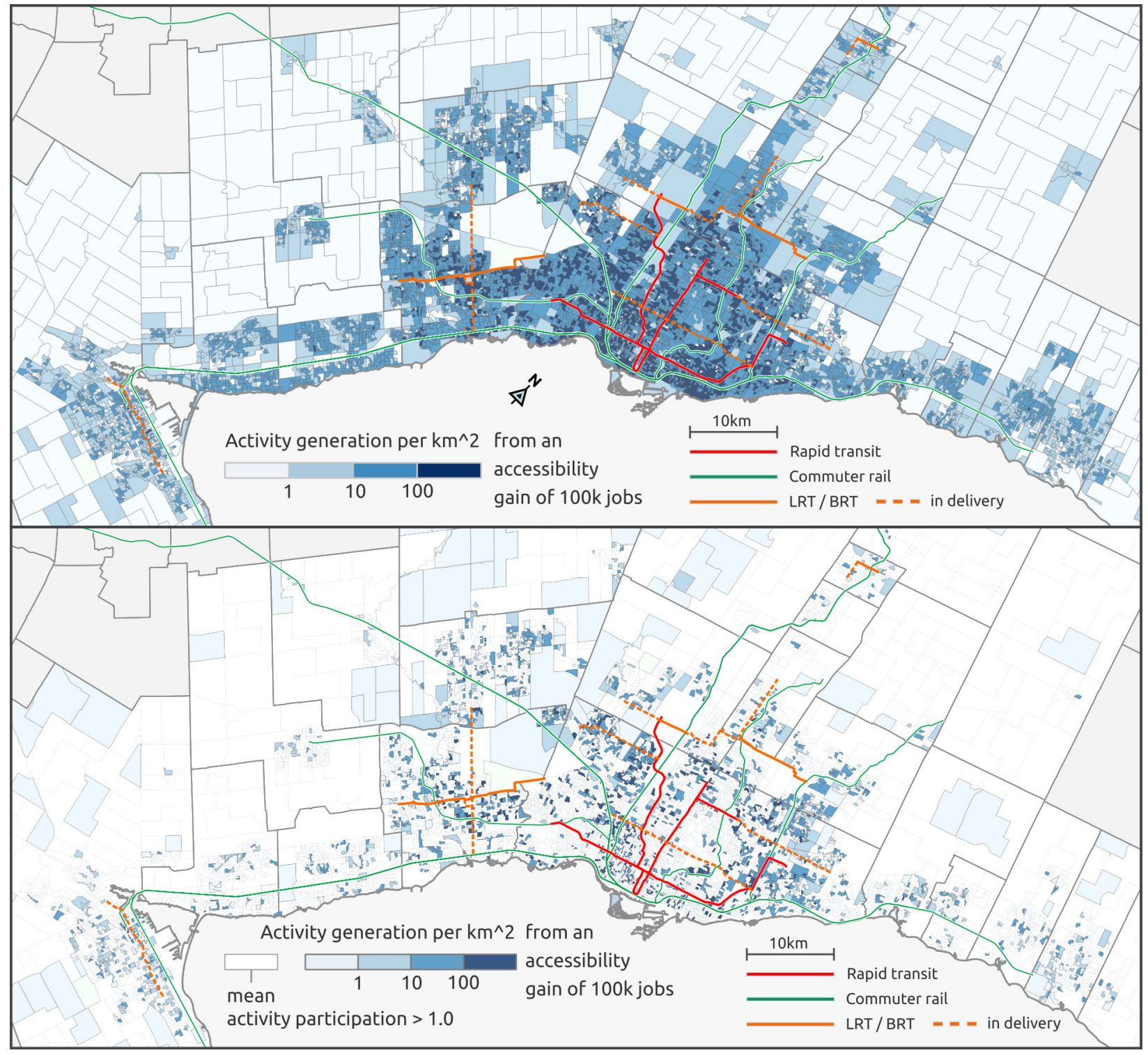

Figure 8 (bottom) only displays results for neighbourhoods with currently low levels of activity participation (where the mean level of activity participation per person is less than one out-of-home activity per day). The dark blue areas on this map can be thought of as high priority neighbourhoods for improving transit accessibility, as they currently have low-levels of activity participation, and would likely see some of the highest returns in activity gains. Focusing on these areas could therefore reduce existing sociospatial inequalities of activity participation, and result in increases in overall levels of transit equity in the region. These dark blue priority areas cluster within the inner-ring suburbs where there are moder- 
ate levels of accessibility already as well as high concentration of low-income and/or zero-car households which currently participate in fewer daily activities relative to other areas. On the other hand, the light blue areas in Figure 8 (bottom) are those where there are currently low levels of activity participation, but moderate improvements in transit accessibility would only have a minor impact, and short-term mobility strategies for improving activity participation would have to include other potential solutions (e.g. carpooling, subsidizing taxis or ride-hailing).

Overlaid on the maps in Figure 8 are existing major transit lines, as well as transit lines which are indelivery (either currently under-construction or are in the planning stage with secured funding, as of April 2019). The in-delivery lines do appear to reach some neighbourhoods that are projected to witness gains in activity participation. However, there are still a number of neighbourhoods within inner-suburban areas that would benefit greatly from improvements in accessibility, that are not currently planned to be reached by higher-order transit in the near future.

\section{Conclusions}

\subsection{Summary of findings}

Our study included exploratory spatial analysis to identify participation deserts, clusters of neighbourhoods where residents have lower than expected rates of daily activity participation. We find that these areas of low activity participation tend to concentrate in the automobile oriented inner-suburbs; poorer, postwar neighbourhoods where existing levels of transit service are not meeting the needs of residents. This hypothesis was further explored in a series of descriptive data explorations, visualizing the links between accessibility, income, car-ownership, and activity participation. The data show quite clearly that participation rates in out-of-home activities for zero-car households are dependent on high levels of transit accessibility. There were large gaps in participation among those with and without cars inside transitpoor neighbourhoods, and these gaps grew smaller with increasing levels of transit access. Parallel to this, we find that zero-car households tend to be located in higher access neighbourhoods, but among zero-car households, there are big differences in accessibility between wealthier and poorer households.

Following the descriptive analyses, we examined the relationship between accessibility and activity participation using multivariate negative binomial models. These models showed that after controlling for other individual and household characteristics, transit accessibility had a small, but significant positive effect on daily activity participation rates. Car ownership and household income also had positive effects (i.e. low-income and zero-car households were less likely to participate in daily activities). We also generated models stratified for different subsets of household income and car-ownership. Low-income households and zero-car households are also the most sensitive to transit accessibility in terms of its effects on increasing activity participation. Zero-car households also tend to be poor households, so increases in transit accessibility are more likely to result in activity gains for low-income households, compared to other income groups. Overall, the greatest potential for participation benefits due to transit investments exists in the centre and inner-ring suburbs. 


\subsection{Study limitations \& directions for future work}

This study had several limitations which could be improved upon in future work. First, there are several unavoidable issues related to the nature and sampling characteristics of the TTS. One issue is that sampling rates were very low in some neighbourhoods $(<3 \%)$ compared to the overall sampling rate of $5 \%$. While this does not pose a serious challenge to the use of descriptive statistics and multivariate models, largely due to the use of individual-level analyses, the unevenness in sampling will cast a shadow of uncertainty over neighbourhood-level averages, such as those used to delineate participation deserts using the GetisOrd $G_{i}^{*}$ statistic. There is a tension here between using low-levels of geography like DAs to find detailed spatial patterns, and using larger aggregation units that would allow for tighter margins of error, but have lower spatial resolution. In the end, given the exploratory nature of the participation deserts, we opted for the former, but a case could be made that larger units should be investigated before policies directed to participation deserts are designed.

A second issue with the TTS, like many regional travel surveys, is that it likely under-reports discretionary activities, short trips or activities, or trips conducted by active modes (Wolf et al., 2003; Stopher et al., 2007). The reasons for under-reporting in the TTS include recall uncertainty, the collection via proxy (e.g. only one household member reports trips for everyone in the household), the lack of collection of recreational trips with no exact destination (e.g. trips for exercise, dog-walking, etc.), and the focus of collection on weekday activities, when arguable, more discretionary activities occur on the weekends. In all cases, it is uncertain whether this under-reporting is related to income, transit accessibility, or car ownership the key variables we have focused on. We did some sensitivity testing with regards to removing short trips $(\leq 1 \mathrm{~km})$ before running models, which resulted in a slightly lower effect of accessibility on activity participation. However, this was likely due to a greater proportion of trips being removed from people who live in areas with greater levels of transit accessibility. Going forward, future travel surveys should do more to reduce under-reporting of trips and activities.

A focus of this research was on transit accessibility and it's effects on activity generation. Despite this, we did not compute accessibility in the multitude of ways it has been quantified in the literature (e.g. Geurs \& Van Wee, 2004; El-Geneidy \& Levinson, 2006). We used a single gravity-based access to jobs measure to model activity generation. In general, there are high levels of correlation between different formulations of place-based accessibility (Kwan, 1998; Stkepniak et al., 2019). But in the future, it might be better to use different types of destinations to predict generation of different types of activities (e.g. use measures of transit access to retail to examine its effects on shopping trips). Moreover, participation in discretionary activities may be better modelled using space-time accessibility measures, rather than the place-based measures employed in our study (Fransen et al., 2018). Generating separate models for participation in different activity types (e.g. work, shopping, etc.) could also result in more nuanced understandings of how accessibility can result in participation benefits for different groups. Similarly, another direction for future research would be to look at the effects of accessibility for more specific SES groups such as by education status, recent immigrants, or the unemployed. More detailed analysis and modelling could possibly also allow for estimating the monetary value of activity generation, since dollar values are predominant in cost-benefit analyses used to decide where to build new transport infrastructure (Thomopoulos et al., 2009; Litman, 2017). This line of research could expand upon work by Stanley et al. 
(2011) who outline an approach using an ordinal choice model of social exclusion.

The cross-sectional design of our study also limits our ability to conclude about causal relations, and brings into question the validity of our method for calculating effect sizes. Relatedly, it is difficult to ascertain the degree to which self-selection is responsible for the findings. It could be that those low-income and zero-car households who have a preference for higher activity levels, choose to pay higher rents to live in the inner city, while those with a preference for less activity, chose to locate in the lower cost suburbs. Without a set of attitudinal and preference questions in the TTS, we are unable to control for this type of self-selection in a cross-sectional analysis. In the future, it would certainly be worthwhile to research these questions longitudinally, either empirically, with more in-depth surveys, or within a simulation framework. There has been some descriptive research analyzing changes in transit accessibility with respect to socioeconomic status over time (e.g. Foth et al., 2013; Farber \& Grandez, 2017), but no research to date has examined this at a more nuanced level with variables pertaining to car-ownership and activity participation rates. Indeed a fruitful direction for future research would be to conduct a longitudinal analysis of changes in the effects of activity participation, partly in relation to increasing socio-spatial inequalities in the city (e.g. increasing suburban poverty). This could be conducted historically (using previous waves of the TTS), as well as continuing to track changes into the future via analyzing ongoing shifts in population distributions and urban form.

Finally, while the objective of our study was to examine how improvements in transit service would result in gains in activity participation, the same types of improvements in transit service could result in modeswitching from private car to public transit (Moniruzzaman \& Páez, 2012). This would have a number of environmental benefits, but could also work towards improved levels of social equity in the region. In our analysis, we observe that there are many low-income drivers in the region. Understanding their mode choice elasticity to transit accessibility could help increase transit ridership while lowering their reliance on auto-based travel and subsequently their mobility costs, such as car loans (Walks, 2018) and fuel costs (Mattioli et al., 2019). This could result in more of their income going towards other necessities of daily life (e.g. housing, healthy food, etc.) or towards leisure activities. To our knowledge, current infrastructure evaluations in the GTHA do not adequately differentiate the mode-choice elasticities with respect to income, largely because this data has not been available until the most recent version of the TTS. Coupled with our findings regarding activity generation, analyzing whether there are higher-elasticities of mode switching among low-income households, at least those who currently own vehicles, would likely enhance evaluation methods and increase the benefits associated with more progressive and fair provision of infrastructure.

\subsection{Policy implications}

Given our findings, this research provides ample evidence in support of transport policies that are directed towards improving the participation rates of low-income and zero-car households, those who we consider to be transport-poor, such as improving public transit in areas where these households concentrate. We contend that existing methods for evaluating transport investments under-value the benefits derived from unlocking suppressed demand for out-of-home activity participation among the transport poor. Adapting 
current transport planning practice to incorporate these components of suppressed demand for activity participation would work progressively towards achieving improved levels of transport equity.

The detailed modelling efforts in this study give rise to a nuanced set of recommendations for how to unlock suppressed demand in different parts of the GTHA. These nuances stem from the spatial distributions of low-income and zero-car households in the region, as well as the sigmoidal response function that describes how improvements in accessibility will not reap the same benefits everywhere in the region. In particular, we see that for most population groups, the steepest part of the sigmoid curve occurs in midrange accessibility levels, signifying that traditional public transit investments in rural areas will likely see little impact on activity generation. At the same time, increases in extremely well served neighbourhoods will similarly have little impact on unlocking suppressed demand, as we do not see transportation service levels in these neighbourhoods acting as a barrier to participation. The challenge is to therefore find lowincome neighbourhoods in the inner suburbs, as these are the places where we have high and growing concentrations of poverty, and where transit levels of service, if improved, would move people up the steepest part of the accessibility-participation sigmoid curve. In other words, this is where we would see the greatest return on investment. We therefore contend that policies that extend the rapid transit network into transit-poor inner suburban neighbourhoods (the dark blue neighbourhoods appearing in the bottom part of Figure 8) should be pursued with priority.

In reality, very few rapid transit expansions will occur over the short-term horizon. Because of this, we also turn our attention towards accessibility improvements achievable through increased provision of surface transit. In the GTHA's inner suburbs in particular, their is excellent coverage of public transit service, and in most places, with high frequency of service. Despite this, we know that buses and streetcars do not reach desirable performance levels during peak-periods due to congestion and signal timing. We therefore recommend an overhaul of the GTHA's surface-level transportation infrastructure, and a reallocation of street lanes to public transit vehicles on a large number of arterials. A suburban network of bus and lightrail right-of-ways will extend high levels of service to a large number of priority neighbourhoods with the potential to greatly increase levels of activity participation and social inclusion. The Highway 7 BRT and King Streetcar project in the GTHA are examples of such strategies that have been extremely successful in both the downtown core and in suburban environments. As well, the maps in this paper indicate that there are areas with low activity participation along the borders of municipalities, which in some cases operate separate local transit service on either side of political jurisdictions. Improving transit access in these areas should therefore also incorporate better connections between local transit agencies, both in terms of fare integration and better network connectivity.

The problem, and need for more solutions do not end there. Our research finds that a large number of low-income, and some zero-car households, live in far more dispersed suburbs, at overall population densities and concentrations of poverty that make the provision of traditional public transit extremely costly and inefficient. Given the costs of public transit investments, substantial transit expansion in such places will likely remain low on a priority list for a very long time. We see two avenues for cost-effective and immediate interventions on the horizon. The first is the adoption and delivery of new transit paradigms such as demand-responsive transit, where the abandonment of the fixed route, and sometimes the use of smaller vehicles, can potentially achieve far greater levels of ridership, higher levels of user satisfaction, and efficiencies in delivery compared to traditional means of transit coverage (Wang et al., 2014). Al- 
ternatively, we must also consider policies that extend mobility and participation benefits to low-income families via enhanced access to auto-mobility, as they can also increase activity participation (Morris \& Blumenberg, 2019). Car-based solutions are controversial because they do not scale well, are not environmentally efficient, and may further add to the divides between those who can and cannot drive. However, programs designed to provide automobile travel to low-income households, while minimizing negative environmental externalities, should be considered and evaluated further. Such programs include government assistance for carpooling and car-sharing schemes or subsidizing taxi and ride-hailing trips for which there are no alternative transit routes. In the longer term, land use planning should enforce urban growth boundaries and promote intensification of land uses within these currently low-density suburban environments. Such strategies would reduce travel distances between activity destinations, make public transit investments more desirable, and result in more equitable levels of accessibility.

As a final note, our research found that low-income households travel less than high-income households, all else being equal. This suggests that the monetary costs of travel, as well as the costs of participating in certain types of activities, might also be factor deterring travel and participation for low-income residents. From a transport planning perspective, this points towards future research which evaluates sensitivity to the monetary costs of travel for different SES groups. Policy which reduces transit fares would certainly be difficult given transit agencies needing to achieve certain revenue targets from fares to offset operational

costs. However, policy could be designed in a progressive fashion; for example, by subsidizing low-income transit riders by taxing wealthy drivers through increased fuel taxes, increased taxes on luxury vehicles, or the deployment of congestion charges. At a higher level, this finding also supports advocating for policy aimed at reducing overall levels of income inequality in the GTHA and beyond. This is not just an issue pertinent for transport planners, but across all disciplines aiming to reduce inequalities and improve well-being in society.

\section{Acknowledgements}

We would like to thank Metrolinx for financially supporting this research. We would also like to thank Matt Routley, Phil Orr, and Matthew Palm for their feedback at different stages of this project. 


\section{References}

Ades, J., Apparicio, P., \& Séguin, A.-M. (2012). Are new patterns of low-income distribution emerging in Canadian metropolitan areas? The Canadian Geographer/Le Géographe canadien, 56(3), 339-361.

Allen, J., \& Farber, S. (2018). How time-use and transportation barriers limit on-campus participation of university students. Travel Behaviour and Society, 13, 174-182.

Allen, J., \& Farber, S. (2019a). A measure of competitive access to destinations for comparing across multiple study regions. Geographical Analysis.

Allen, J., \& Farber, S. (2019b). Sizing up transport poverty: A national scale accounting of low-income households suffering from inaccessibility in Canada, and what to do about it. Transport Policy, 74, 214-223.

Ben-Akiva, M. E., \& Lerman, S. R. (1985). Discrete choice analysis: theory and application to travel demand (Vol. 9). MIT press.

Blumenberg, E., Brown, A., \& Schouten, A. (2018). Car-deficit households: determinants and implications for household travel in the us. Transportation, 1-23.

Casas, I. (2007). Social exclusion and the disabled: An accessibility approach*. The Professional Geographer, 59(4), 463-477.

Cervero, R., \& Kockelman, K. (1997). Travel demand and the 3ds: density, diversity, and design. Transportation Research Part D: Transport and Environment, 2(3), 199-219.

Churchill, S. A., \& Smyth, R. (2019). Transport poverty and subjective wellbeing. Transportation Research Part A: Policy and Practice, 124, 40-54.

Cordera, R., Coppola, P., dell'Olio, L., \& Ibeas, Á. (2017). Is accessibility relevant in trip generation? modelling the interaction between trip generation and accessibility taking into account spatial effects. Transportation, 44(6), 1577-1603.

Di Ciommo, F., \& Shiftan, Y. (2017). Transport equity analysis. Transport Reviews, 37(2), 139-151.

El-Geneidy, A., Buliung, R., Diab, E., van Lierop, D., Langlois, M., \& Legrain, A. (2016). Non-stop equity: Assessing daily intersections between transit accessibility and social disparity across the Greater Toronto and Hamilton Area (GTHA). Environment and Planning B: Planning and Design, 43(3), 540560.

El-Geneidy, A., \& Levinson, D. M. (2006). Access to destinations: Development of accessibility measures.

Ewing, R., DeAnna, M., \& Li, S.-C. (1996). Land use impacts on trip generation rates. Transportation research record, 1518(1), 1-6.

Farber, S., \& Fu, L. (2017). Dynamic public transit accessibility using travel time cubes: Comparing the effects of infrastructure (dis) investments over time. Computers, Environment and Urban Systems, 62, $30-40$.

Farber, S., \& Grandez, M. (2017). Transit accessibility, land development and socioeconomic priority: A typology of planned station catchment areas in the Greater Toronto and Hamilton Area. fournal of Transport and Land Use, 10(1).

Farber, S., Mifsud, A., Allen, J., Widener, M. J., Newbold, K. B., \& Moniruzzaman, M. (2018). Transportation Barriers to Syrian Newcomer Participation and Settlement in Durham Region. fournal of Transport Geography.

Feitelson, E. (2002). Introducing environmental equity dimensions into the sustainable transport discourse: issues and pitfalls. Transportation Research Part D: Transport and Environment, 7(2), 99-118. 
Foth, N., Manaugh, K., \& El-Geneidy, A. M. (2013). Towards equitable transit: examining transit accessibility and social need in Toronto, Canada, 1996-2006. Journal of transport geography, 29, 1-10.

Fransen, K., Farber, S., Deruyter, G., \& De Maeyer, P. (2018). A spatio-temporal accessibility measure for modelling activity participation in discretionary activities. Travel behaviour and society, 10, 10-20.

Garrett, M., \& Taylor, B. (1999). Reconsidering social equity in public transit. Berkeley Planning fournal, 13(1).

Getis, A., \& Ord, J. K. (1992). The analysis of spatial association by use of distance statistics. In Perspectives on spatial data analysis (Vol. 24, pp. 189-206). Springer.

Geurs, K. T., \& Van Wee, B. (2004). Accessibility evaluation of land-use and transport strategies: review and research directions. Fournal of Transport geography, 12(2), 127-140.

Hansen, W. G. (1959). How accessibility shapes land use. Journal of the American Institute of planners, 25(2), 73-76.

Hanson, S., \& Schwab, M. (1987). Accessibility and intraurban travel. Environment and Planning A, 19(6), 735-748.

Hertel, S., Keil, R., \& Collens, M. (2015). Switching Tracks: Toward transit equity in the Greater Toronto and Hamilton Area. Toronto: City Institute at York University.

Hodgson, F., \& Turner, J. (2003). Participation not consumption: the need for new participatory practices to address transport and social exclusion. Transport Policy, 10(4), 265-272.

Hulchanski, J. D. (2010). The three cities within Toronto. Cities Centre: University of Toronto.

Karner, A., \& Niemeier, D. (2013). Civil rights guidance and equity analysis methods for regional transportation plans: a critical review of literature and practice. Journal of Transport Geography, 33, 126-134.

Kitamura, R., Akiyama, T., Yamamoto, T., \& Golob, T. F. (2001). Accessibility in a metropolis: Toward a better understanding of land use and travel. Transportation Research Record, 1780(1), 64-75.

Koenig, J.-G. (1980). Indicators of urban accessibility: theory and application. Transportation, 9(2), 145172.

Kwan, M.-P. (1998). Space-time and integral measures of individual accessibility: a comparative analysis using a point-based framework. Geographical analysis, 30(3), 191-216.

Litman, T. (2003). Social inclusion as a transport planning issue in Canada. In FIA foundation G7 comparison paper. (Presented at the European Transport Conference held in Strassbourg in June, 2003)

Litman, T. (2017). Evaluating public transit benefits and costs. Victoria Transport Policy Institute Victoria, BC, Canada.

Litman, T. (2019). Evaluating transportation equity. Victoria Transport Policy Institute Victoria, BC, Canada.

Lucas, K. (2012). Transport and social exclusion: Where are we now? Transport policy, 20, 105-113.

Lucas, K., Bates, J., Moore, J., \& Carrasco, J. A. (2016). Modelling the relationship between travel behaviours and social disadvantage. Transportation Research Part A: Policy and Practice, 85, 157-173.

Manaugh, K., Badami, M. G., \& El-Geneidy, A. M. (2015). Integrating social equity into urban transportation planning: A critical evaluation of equity objectives and measures in transportation plans in North America. Transport Policy, 37, 167-176.

Martens, K. (2006). Basing transport planning on principles of social justice. Berkeley Planning fournal, 19(1), 1-17.

Martens, K. (2016). Transport justice: Designing fair transportation systems. Routledge. 
Mattioli, G., Philips, I., Anable, J., \& Chatterton, T. (2019). Vulnerability to motor fuel price increases: Socio-spatial patterns in england. Fournal of Transport Geography, 78, 98-114.

McCray, T., \& Brais, N. (2007). Exploring the role of transportation in fostering social exclusion: The use of GIS to support qualitative data. Networks and Spatial Economics, 7(4), 397-412.

McNally, M. G. (2000). The four step model. Institute of Transportation Studies, University of California, Irvine.

Meyer, M., \& Miller, E. (2001). Urban transportation planning (2nd ed.). McGraw-Hill Education.

Moniruzzaman, M., \& Páez, A. (2012). Accessibility to transit, by transit, and mode share: application of a logistic model with spatial filters. Journal of Transport Geography, 24, 198-205.

Morris, E. A., \& Blumenberg, E. (2019). Does lacking a car put the brakes on activity participation? private vehicle access and access to opportunities among low-income adults. Presented at 98th Annual Meeting of the Transportation Research Board, Washington, D.C., 2019.

Östh, J., Lyhagen, J., \& Reggiani, A. (2016). A new way of determining distance decay parameters in spatial interaction models with application to job accessibility analysis in sweden. European fournal of Transport and Infrastructure Research, 16(2).

Owen, A., \& Levinson, D. M. (2015). Modeling the commute mode share of transit using continuous accessibility to jobs. Transportation Research Part A: Policy and Practice, 74, 110-122.

Páez, A., Farber, S., Mercado, R., Roorda, M., \& Morency, C. (2013). Jobs and the single parent: An analysis of accessibility to employment in toronto. Urban Geography, 34(6), 815-842.

Páez, A., Scott, D. M., \& Morency, C. (2012). Measuring accessibility: positive and normative implementations of various accessibility indicators. Fournal of Transport Geography, 25, 141-153.

Pereira, R. H., Schwanen, T., \& Banister, D. (2017). Distributive justice and equity in transportation. Transport Reviews, 37(2), 170-191.

Preston, J., \& Rajé, F. (2007). Accessibility, mobility and transport-related social exclusion. Fournal of Transport Geography, 15(3), 151-160.

Rey, S. J., \& Anselin, L. (2007). PySAL: A Python Library of Spatial Analytical Methods. The Review of Regional Studies, 37(1), 5-27.

Roorda, M. J., Páez, A., Morency, C., Mercado, R., \& Farber, S. (2010). Trip generation of vulnerable populations in three Canadian cities: a spatial ordered probit approach. Transportation, 37(3), 525548.

Sengupta, R. P., Fordham, J., Day, N., Macfarlane, R., \& Campbell, M. (2013). Next Stop Health: Transit Access and Health Inequities in Toronto. Toronto Public Health.

Stanley, J., Hensher, D. A., Stanley, J., Currie, G., Greene, W. H., \& Vella-Brodrick, D. (2011). Social exclusion and the value of mobility. Fournal of Transport Economics and Policy (FTEP), 45(2), 197-222.

Stkepniak, M., Pritchard, J. P., Geurs, K. T., \& Goliszek, S. (2019). The impact of temporal resolution on public transport accessibility measurement: Review and case study in poland. fournal of transport geography, 75, 8-24.

Stopher, P., FitzGerald, C., \& Xu, M. (2007). Assessing the accuracy of the Sydney Household Travel Survey with GPS. Transportation, 34(6), 723-741.

Thill, J.-C., \& Kim, M. (2005). Trip making, induced travel demand, and accessibility. Fournal of Geographical Systems, 7(2), 229-248.

Thomopoulos, N., Grant-Muller, S., \& Tight, M. (2009). Incorporating equity considerations in transport infrastructure evaluation: Current practice and a proposed methodology. Evaluation and program 
planning, 32(4), 351-359.

Venables, W., Ripley, B., \& Isbn, S. (2002). Statistics Complements to Modern Applied Statistics with S.

Vickerman, R. W. (1974). Accessibility, attraction, and potential: a review of some concepts and their use in determining mobility. Environment and Planning A, 6(6), 675-691.

Walks, A. (2013). Income inequality and polarization in Canada's cities: An examination and new form of measurement. Cities Centre, University of Toronto.

Walks, A. (2018). Driving the poor into debt? automobile loans, transport disadvantage, and automobile dependence. Transport policy, 65, 137-149.

Wang, C., Quddus, M., Enoch, M., Ryley, T., \& Davison, L. (2014). Multilevel modelling of Demand Responsive Transport (DRT) trips in Greater Manchester based on area-wide socio-economic data. Transportation, 41(3), 589-610.

Wolf, J., Oliveira, M., \& Thompson, M. (2003). The impact of trip underreporting on VMT and travel time estimates: preliminary findings from the California statewide household travel survey GPS study. Transportation Research Record, 1854, 189-198.

Wood, S. N., Pya, N., \& Säfken, B. (2016). Smoothing parameter and model selection for general smooth models. Journal of the American Statistical Association, 111(516), 1548-1563.

Zhang, Q., Clifton, K. J., Moeckel, R., \& Orrego-Oñate, J. (2019). Household trip generation and the built environment: Does more density mean more trips? Transportation Research Record. 


\section{Appendix}

Table 5: Model parameters for sigmoidal transformation of accessibility for subsets of household income and car ownership

\begin{tabular}{|c|c|c|c|c|c|c|c|c|c|}
\hline \multirow{2}{*}{$\begin{array}{l}\text { Household } \\
\text { income }\end{array}$} & \multirow{2}{*}{$\begin{array}{l}\text { Vehicles per } \\
\text { adult (VA) }\end{array}$} & \multirow[b]{2}{*}{$\mathbf{N}$} & \multirow[b]{2}{*}{$\mathbf{n}$} & \multirow{2}{*}{$\begin{array}{l}\text { Mean daily } \\
\text { activities }\end{array}$} & \multicolumn{5}{|c|}{ Estimated Model Parameters } \\
\hline & & & & & $\beta_{A}$ & $k$ & $A_{m}$ & $p$-value & $\rho$ \\
\hline$<\$ 40 \mathrm{k}$ & $\mathrm{VA}=0$ & 264,475 & 9,934 & 0.82 & 0.24 & -0.18 & 41 & 0.000 & 0.14 \\
\hline$<\$ 40 \mathrm{k}$ & $0<\mathrm{VA}<0.5$ & 109,122 & 3,688 & 0.85 & 0.18 & -0.30 & 39 & 0.049 & 0.12 \\
\hline$<\$ 40 \mathrm{k}$ & $\mathrm{VA}=0.5$ & 217,567 & 10,320 & 0.99 & -0.10 & -0.08 & 22 & 0.111 & 0.08 \\
\hline$<\$ 40 \mathrm{k}$ & $0.5<\mathrm{VA}<1$ & 52,502 & 2,081 & 0.91 & -0.08 & -0.11 & 19 & 0.480 & 0.14 \\
\hline$<\$ 40 \mathrm{k}$ & $\mathrm{VA}>=1$ & 189,582 & 9,888 & 1.27 & 0.11 & -0.30 & 38 & 0.091 & 0.04 \\
\hline$\$ 40 \mathrm{k}-\$ 60 \mathrm{k}$ & $\mathrm{VA}=0$ & 85,983 & 3,492 & 1.10 & 0.24 & -0.18 & 31 & 0.000 & 0.17 \\
\hline$\$ 40 \mathrm{k}-\$ 60 \mathrm{k}$ & $0<\mathrm{VA}<0.5$ & 115,998 & 3,997 & 0.89 & -0.10 & -0.24 & 20 & 0.027 & 0.18 \\
\hline$\$ 40 \mathrm{k}-\$ 60 \mathrm{k}$ & $\mathrm{VA}=0.5$ & 200,721 & 9,704 & 1.08 & -0.09 & -0.06 & 22 & 0.264 & 0.07 \\
\hline$\$ 40 \mathrm{k}-\$ 60 \mathrm{k}$ & $0.5<\mathrm{VA}<1$ & 93,395 & 3,768 & 0.97 & 0.08 & -0.06 & 18 & 0.605 & 0.09 \\
\hline$\$ 40 \mathrm{k}-\$ 60 \mathrm{k}$ & $\mathrm{VA}>=1$ & 213,946 & 10,928 & 1.36 & 0.07 & -0.29 & 48 & 0.641 & 0.05 \\
\hline$\$ 60 \mathrm{k}-\$ 100 \mathrm{k}$ & $\mathrm{VA}=0$ & 92,831 & 3,868 & 1.21 & 0.25 & -0.28 & 40 & 0.000 & 0.16 \\
\hline$\$ 60 \mathrm{k}-\$ 100 \mathrm{k}$ & $0<\mathrm{VA}<0.5$ & 148,083 & 5,547 & 0.97 & -0.09 & -0.18 & 42 & 0.251 & 0.18 \\
\hline$\$ 60 \mathrm{k}-\$ 100 \mathrm{k}$ & $\mathrm{VA}=0.5$ & 289,144 & 13,546 & 1.17 & 0.15 & -0.30 & 39 & 0.000 & 0.09 \\
\hline$\$ 60 \mathrm{k}-\$ 100 \mathrm{k}$ & $0.5<\mathrm{VA}<1$ & 182,766 & 7,383 & 1.05 & 0.25 & -0.25 & 45 & 0.112 & 0.11 \\
\hline$\$ 60 \mathrm{k}-\$ 100 \mathrm{k}$ & $\mathrm{VA}>=1$ & 428,974 & 21,237 & 1.47 & 0.17 & -0.13 & 49 & 0.048 & 0.04 \\
\hline$\$ 100 k-\$ 125 k$ & $\mathrm{VA}=0$ & 27,407 & 1,338 & 1.26 & 0.24 & -0.28 & 36 & 0.012 & 0.12 \\
\hline$\$ 100 k-\$ 125 k$ & $0<\mathrm{VA}<0.5$ & 58,579 & 2,244 & 1.04 & 0.24 & -0.10 & 31 & 0.006 & 0.17 \\
\hline$\$ 100 k-\$ 125 k$ & $\mathrm{VA}=0.5$ & 125,435 & 6,344 & 1.31 & -0.04 & -0.10 & 21 & 0.423 & 0.09 \\
\hline$\$ 100 \mathrm{k}-\$ 125 \mathrm{k}$ & $0.5<\mathrm{VA}<1$ & 116,076 & 4,546 & 1.14 & 0.05 & -0.25 & 20 & 0.190 & 0.12 \\
\hline$\$ 100 k-\$ 125 k$ & $\mathrm{VA}>=1$ & 267,324 & 13,033 & 1.52 & 0.07 & -0.30 & 29 & 0.032 & 0.05 \\
\hline$\$ 125 k+$ & $\mathrm{VA}=0$ & 27,034 & 1,500 & 1.37 & 0.18 & -0.29 & 34 & 0.101 & 0.12 \\
\hline$\$ 125 k+$ & $0<\mathrm{VA}<0.5$ & 62,544 & 2,568 & 1.11 & 0.24 & -0.18 & 49 & 0.103 & 0.17 \\
\hline$\$ 125 k+$ & $\mathrm{VA}=0.5$ & 195,657 & 10,519 & 1.40 & 0.08 & -0.30 & 26 & 0.002 & 0.09 \\
\hline$\$ 125 k+$ & $0.5<\mathrm{VA}<1$ & 211,944 & 8,507 & 1.23 & 0.17 & -0.29 & 29 & 0.000 & 0.10 \\
\hline$\$ 125 k+$ & $\mathrm{VA}>=1$ & 584,354 & 29,240 & 1.58 & 0.14 & -0.23 & 24 & 0.000 & 0.05 \\
\hline decline & $\mathrm{VA}=0$ & 97,645 & 4,405 & 0.73 & 0.12 & -0.31 & 27 & 0.017 & 0.17 \\
\hline decline & $0<\mathrm{VA}<0.5$ & 115,399 & 4,320 & 0.84 & 0.07 & -0.31 & 21 & 0.095 & 0.11 \\
\hline decline & $\mathrm{VA}=0.5$ & 209,902 & 11,298 & 1.03 & 0.02 & -0.29 & 22 & 0.492 & 0.06 \\
\hline decline & $0.5<\mathrm{VA}<1$ & 174,770 & 7,167 & 1.03 & 0.18 & -0.30 & 34 & 0.011 & 0.08 \\
\hline decline & $\mathrm{VA}>=1$ & 386,262 & 21,043 & 1.31 & 0.16 & -0.07 & 35 & 0.001 & 0.03 \\
\hline
\end{tabular}

